\title{
PROFANO E PROFANADO: \\ problemáticas do corpo e reverberações nas artes visuais
}

\section{Profane and desecrated:}

\section{body issues and their reverberations in the visual arts}

\author{
Maristela Müller \\ Universidade do Estado de Santa Catarina - UDESC
}

Resumo: Ao longo do percurso histórico da humanidade desenvolveram-se diferentes concepções acerca do corpo, que se desdobraram em problemáticas potentes na religião, na filosofia, na literatura, nas artes e na educação. O presente artigo encontra-se dividido em duas principais partes: a primeira se refere ao corpo profano e a segunda versa o corpo profanado. Sendo estas, duas vias possíveis de se pensar a arte contemporânea e sua complexa reverberação para o ensino das Artes Visuais.

Palavras-chave: Ensino das Artes Visuais; Problemáticas do corpo; Profano e profanado.

Abstract: Throughout the history of humanity different conceptions about the body were developed, which unfolded in powerful problems in the religion, philosophy, literature, art, visual arts and education. This article is divided in two main parts: the first refers to the profane body, and the second deals with the desecrated body. These are two possible of the ways to think contemporary art and its complex reverberation in the teaching of the Visual Arts.

Keywords: Teaching of the Visual Arts; Body issues; Profane and desecrated. 
No presente artigo pretende-se problematizar a temática do corpo nas Artes Visuais sob dois vieses: corpo profano e o corpo profanado. Para isso, retorna-se alguns séculos e décadas, a fim de perceber diferentes concepções presentes na cultura ocidental sobre aquilo que caracteriza, identifica e situa o ser humano no mundo, quer seja, o corpo. Nesse sentido, compreende-se o corpo como uma condição humana inerente, essencial, física, carnal e intelectual.

$\mathrm{O}$ artigo encontra-se dividido em duas principais partes: a primeira se refere ao corpo profano, que é apresentado por meio de recortes teóricos e artísticos que abordam o corpo como meio para realizar ações transgressoras e o corpo como espaço de transgressão, em sua unidade carnal/intelectual. $\mathrm{Na}$ segunda parte, aborda-se o corpo profanado, um corpo carnal, visceral, íntimo, sofrido, sensível, performático, afetado pela catástrofe e que se manifesta como espaço aberto para a transgressão, questionamentos e reflexões.

Ao longo do artigo apresenta-se, sequencialmente, o corpo profano e o corpo profanado. Isso não significa que, ao longo da história, as concepções sobre o corpo e suas representações nas artes tenham sido produzidas em uma lógica linear, sequencial ou progressiva. Pelo contrário, os dois termos aqui adotados para falar sobre o corpo nas Artes Visuais percorrem diferentes contemporaneidades. Em determinados momentos da história da arte se fazem mais ou menos presentes, sendo temáticas e problemáticas revisitadas, em alguns casos, no mesmo trabalho ou pelo mesmo artista.

\section{O Corpo Profano}

O mundo não é aquilo que eu penso, mas aquilo que eu vivo.

(MERLEAU-PONTY, 1994, p. 14)

A falar do corpo profano, automaticamente, se pensa na oposição entre sagrado e profano. Abordar o corpo como sagrado, como imagem e semelhança de Deus ou na perspectiva de elevar o espírito e rechaçar o corpo por ser considerado reduto das paixões, do ódio, da preguiça, dos prazeres, das vaidades e dos pecados, como por muito tempo aconteceu, não é o foco deste trabalho. Não se pretende trazer a dualidade entre corpo e espírito e endossar um sentimento de estranheza com relação ao corpo, pois o corpo é o que há de mais próximo e familiar em cada um(a). Pretende-se enfatizar as concepções sobre o corpo que continuam potentes para se pensar o tempo recente e as reverberações nas Artes Visuais.

Na Idade Contemporânea vigoram distintos pensamentos sobre o corpo, um deles é exposto por Merleau-Ponty (1908-1961), que concebe o corpo como um todo. Um corpo atual, operante e atual, móvel e visível, vidente e visível, tocante e tocado, senciente-sensível. Tal perspectiva reverbera no modo de produzir e compreender as artes. Para Merleau-Ponty, o corpo não é apenas um objeto visado pela consciência, ele é a própria consciência encarnada. O corpo não é apenas matéria a ocupar uma porção no espaço, não é a carne dissociada das sensações, nem um mero depositário da razão, pois se assim fosse, não haveria de se tratar do "corpo de um homem, e nem 
haveria humanidade" (MERLEAU-PONTY, 2004, p.17). O filósofo não separa o corpo da mente, a sensação do pensar, o ver do raciocinar, a percepção da razão, ao afirmar que: "Basta que eu veja alguma coisa para saber juntar-me a ela e atingi-la [...]" (MERLEAU-PONTY, 2004, p.16). Então, trata-se de um corpo que pensa, um todo móvel que mantém as coisas em circuito ao seu redor, que se desloca no mundo visível, que o sente mundo de maneira singular e que faz parte dele.

Merleau-Ponty critica o modelo cartesiano, de René Descartes (1596-1650). Critica o pensamento que se recusa a frequentar 0 visível, que manipula as coisas sem querer habitá-las. O filósofo não vislumbra um mundo fechado em conceitos generalizadores, pois o modo de pensar depende das sensações de cada corpo, das vivências de cada pessoa, pois:

[...] o mundo é aquilo que nós percebemos. [...] $\bigcirc$ mundo não é aquilo que eu penso, mas aquilo que eu vivo; eu estou aberto ao mundo, comunico-me indubitavelmente com ele, mas não o possuo, ele é inesgotável. "Há um mundo", ou, antes, "há o mundo"; dessa tese constante de minha vida não posso nunca inteiramente dar razão (MERLEAU-PONTY, 1994, p. 14).

Através da citação, o filósofo considera que a percepção do mundo é realizada pelos sentidos e pelo pensar de maneira entrelaçada. Merleau-Ponty busca perder 0 artificialismo, o pensamento de sobrevoo, o pensamento científico e generalizador, para se colocar num "há" prévio, no solo do mundo sensível, na possibilidade de "ir as coisas mesmas" e se confrontar constantemente com o mundo real para habitá-lo. Perceber o mundo. Se abrir ao mundo. Entrelaçar-se com ele. Estar sensível aos acontecimentos que rodeiam - corpo atual, no modo singular de perceber as coisas, como que faz o artista Cézanne.

Para Merleau-Ponty, as pinturas de Cézanne exemplificam a questão do envolvimento do corpo com o mundo. Por isso, a pintura é considerada a grande arte, a ciência secreta do ver, onde o pintor utiliza seu corpo, ou seja, os sentidos vinculados à razão. Assim, questiona: De que valeria nossa inteligibilidade sem a relação da matéria do corpo? De que valeria à pintura se houvesse apenas nosso espírito dissociado da percepção, dos sentidos, do movimento do corpo? Por isso, um espírito não poderia pintar, diz Merleau-Ponty, pois "é oferecendo o corpo ao mundo que o pintor transforma o mundo em pintura" (MERLEAU-PONTY, 2004, p. 16). Através do corpo como um todo, que se desloca, que se abre, se oferece ao mundo e se entrelaça com ele é que o pintor realiza a ciência secreta que transforma o mundo em pintura.

O pintor não somente pinta, mas exprime suas opiniões ao perceber o mundo e ao transformá-lo em pintura. $O$ pintor pensa por meio da pintura. Seu corpo, sua visão e seu pensamento se tornam gestos, se tornam pintura. Dentro do seu ofício o pintor se encontra livre para emitir seu juízo sobre o que vê, no seu modo de ver. Cézanne, por exemplo, ambicionava pintar

Revista Moringa - Artes do Espetáculo, João Pessoa, UFPB, v. 9 n. 2, jul/dez 2018, p. 63 a 72

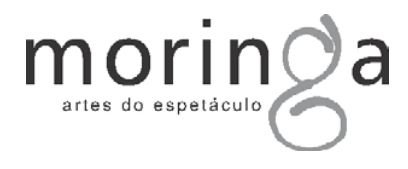


a impressão da natureza em sua origem, o mundo primordial, do corpo se entrelaçando com o mundo. Sendo que cada vez era diferente, único, porque na relação entre o corpo e o mundo sempre há algo de novo, há outras sensações e percepções a serem experimentadas.

A perspectiva merleau-pontyana de pensar o corpo atinge as artes, onde o corpo não é considerado um acidente feliz ou desgraçado que coloca o ser humano no mundo implacável da matéria. Corpo: "Es una adherencia de la cual no se escapa y que ninguna metáfora podría confundir con la presencia de un objeto exterior; es una unión a la cual nada podría alterarle [...]" (LEVINAS, 2001, p. 16). O corpo é aderência que produz um sentimento de unidade entre o eu e o corpo, uma união que não se altera. Sobre a aderência, descrita por Levinas (2001), encontra-se referência precedente nos escritos de Merleau-Ponty (2000, p. 138), que fala do corpo enquanto "(...) aderência carnal do sentiente ao sentido e do sentido ao sentiente". A aderência se refere ao enlace total, mistura homogênea entre o ser ciente e os sentidos.

Trazer a aderência e a equidade carnal/intelectual do corpo para a esfera da vida, da vivência, da experiência, da arte, significa atestar igualdade aos sentidos, que por tanto tempo se mantiveram rebaixados pelo status do intelecto. $O$ corpo profano é significativo e representativo na arte, pois acentua os sentidos, as sensações, a percepção e as ideias que ocorrem a partir das experiências e experimentações. Profano se refere aquilo que é impuro, alheio as questões sagradas, está ligado ao mundano, ao material, à transgressão, longe das questões consideradas elevadas. O profano pode estar ligado tanto à beleza quanto a feiura, em um misto de sedução e repulsão.

O corpo profano provoca as convenções sociais e se mostra na Olympia e no Almoço na Relva, de Édouard Manet. Aparece no Jardim das Delícias de Hieronymus Bosch. Nos corpos debochados e cadavéricos dos desenhos, pinturas e gravuras de Goya. Evidencia a sensualidade, a libidinagem, a volúpia, a concupiscência, a luxúria, a nudez, a desnudez, o desejo e a opulência da carne nos corpos pintados por Peter Paul Rubens, François Boucher e Gustave Courbet. Mostra-se no corpo erótico e pornográfico. É evidenciado no realismo em A Origem do Mundo, de Courbet. $\mathrm{Na}$ beleza, na feiura, nas distorções, na ausência de proporção e no excesso de tinta, ao representar corpos que começam a expandir os limites da tela.

O corpo profano se faz presente nas representações do cenário artístico brasileiro ao levantar questões gênero, ao debater e incidir sobre símbolos religiosos, ao transfigurar figuras sagradas. Estas articulações com o profano foram vistas, por exemplo, na exposição "Queermuseu cartografias da diferença na arte da brasileira", com a curadoria de Gaudêncio Fidelis, no ano de 2017, que reuniu trabalhos de 85 artistas. No entanto, foi cancelada por conta de movimentos contrários à exposição. Fato que leva a continuar questionando: de que maneira às representações do corpo são ensinadas, 
pensadas, tratadas, mostradas ou escondidas nas Artes Visuais?

\section{O Corpo Profanado}

[Somos] de carne, de bife, de sangue, de lágrimas, de suores, de merda, de inteligência, de ternura, de outras coisas ainda, ao infinito, sem que nenhuma negue as outras, ou melhor: cada uma saudando as outras. (GENET, 2002, p. 75-76)

Profanação se refere à violação, rasgar e romper com o sagrado, despedaçar, afrontar asquerosamente e mutilar convenções. Assim, a profanação está para além do profano, da transgressão pela transgressão, pois ao mesmo tempo em que transgride, também questiona e gera reflexões sobre a problemática do corpo e do ser humano no mundo. O corpo profanado remete ao corpo que afeta e é afetado, corpo atingido pelas tragédias, pelas guerras e pelo genocídio. A história da humanidade é marcada por conflitos, disputas e guerras, sendo a mais perversa e nefasta a Segunda Guerra Mundial e os campos de concentração.

A Segunda Guerra evidencia o holocausto, - sacrifício, a morte, a mutilação, a catástrofe, o sangue, a dor, a pele, o corpo. No horror do genocídio o corpo é apontado e pontuado em virtude de ter sido diretamente afetado. O que marca as pessoas aprisionadas? $\mathrm{O}$ que se vê na morte? O que caracteriza a presença de alguém? O corpo. A partir do Nazismo, dos campos de concentração (como em Auschwitz) e da Segunda Guerra começase a realizar outras reflexões nas artes (poesia, literatura, cinema, teatro, plásticas) e em outras áreas do conhecimento.

Passa-se a olhar para o corpo na arte não apenas como algo sagrado ou profano, em seu ideal de beleza e erotismo, com riqueza de detalhes, na representação de simetria, proporção, equilíbrio e beleza. Passa-se a considerar o corpo enquanto espaço de questionamentos e reflexões em meio às sensações, transgressões e profanações. Passa-se a olhar o corpo marcado pela tragédia e, não por acaso, diversos autores interrogam-se sobre a possibilidade de se falar ou produzir poesia e arte após Auschwitz, como Adorno (2009), Marcuse (2009), Levinas (2001), Seligmann-Silva e Nestrovski (2000), Sánchez (2004). Questionamento realizado por estudiosos de diferentes linhas teóricas que transbordaram para as artes, principalmente na arte contemporânea, a qual se vale do corpo em uma infinidade de trabalhos. Após Auschwitz não é mais possível pensar o corpo como antes.

No centro da discussão encontra-se a $S h o a h^{1}$, uma espécie de buraco negro ou evento-limite, que em Seligmann-Silva e Nestrovski (2000) está aponta como sendo um evento catastrófico real, como no caso da Segunda Guerra e dos campos de

\footnotetext{
1 Shoah - significa calamidade. A palavra Shoah substitui o termo holocausto, pois o holocausto possui um sentido religioso para os judeus, que remete a expiação dos pecados através do fogo. Na prática nazista ocorreu um genocídio, não um holocausto, então usa-se a palavra Shoah (calamidade e catástrofe) para se remeter ao fato.
} 
concentração. Para discorrer a seu respeito faz-se necessária uma memória sem distorção. Aqui está postulado um problema que é o buraco negro da impossibilidade de se falar a respeito de fatos catastróficos. Como é possível representar ou escrever sobre algo chocante? Será que a Shoah, como um evento singular e incomparável, pode ser estudada?

As questões levantadas não anulam as possibilidades de representação, mas colocam limites para que a Shoah não seja banalizada e distorcida. O historiador, o filósofo, o artista permanece em meio à necessidade de representar e escrever sobre o evento, ao mesmo tempo, diante da consciência da impossibilidade de cumprir essa tarefa, por falta de aparato conceitual. Não que haja algum problema na língua ou na escrita, mas a Shoah é o excesso de real, o qual nunca se dará conta, pois vai além da capacidade humana de representar e investigar.

A dificuldade de explicar a Shoah não reside apenas para filósofos, estudiosos, historiadores e artistas. A literalidade dos fatos, a experiência traumática marcada pelo excesso confunde, inclusive, quem a vivenciou. A vivência real do choque faz com que o sujeito submetido à catástrofe mobilize todo seu aparato psíquico e corporal para defesa, o que pode causar distorções na percepção e na memória.

A partir do mesmo questionamento, Pedro Sánchez (2004), não aborda a problemática do corpo e da representação como condenada, porque por meio da representação, da arte, é que caminhos são abertos para outras reflexões sobre o corpo. Sánchez não propõe outra forma de representação, mas possui entendimento de que qualquer forma de representação não abarca a totalidade da catástrofe, do real, da complexidade do corpo e sua relação com 0 mundo. Não que a representação seja falha, que as palavras sejam parcas. Contudo, a extensão e a complexidade da realidade são maiores do que se possa considerar.

$\mathrm{Na}$ representação do evento-limite, por exemplo, o corpo se apresenta como estranhamento. Algo que causa horror, pois é possível se deparar com artistas utilizando objetos, sangue, vísceras, excrementos, fluídos, pruridos, carne, ossos e pele nos trabalhos artísticos, na reverberação da experiência da catástrofe e da profanação dos corpos. Neste contexto, a arte contemporânea se apresenta mais como questão do que como resposta, mais como problema do que resolução, mais como abjeto $^{2} \mathrm{e}$ profanação, do que sagrado ou profano.

\footnotetext{
2 A etimologia da palavra abjeto traz como significado aquilo que é desprezível. Por isso, remete ao afastamento, a experiência de atração e repulsão. A abjeção ocorre na experiência corporal, na sensação, na comoção, na agitação, na rebelião inassimilável do ser, na dor que afeta e fragiliza. Para Julia Kristeva: "Hay en la abyecctión una de esas violentas y oscuras rebeliones del ser contra aquello que lo amenaza y que le parece venir de un afuera o de un adentro exorbitante, arrojado al lado de lo posible y de lo tolerable, de lo pensable. Allí está, muy cerca, pero inasimilable" (Kristeva. 1988, p.7). Nos momentos, ou entre os momentos de inquietação o(a) artista possui o desejo de colocar para fora de seu corpo o que atormenta e consome, onde "[...] yo me expulso, yo me escupo, yo me abyecto (...)" (Kristeva, 1988, p. 10), para que 0 inassimilável fique preso no trabalho, na tentativa de afastar-se de si. No entanto, continua próximo, presente por meio da arte no jogo ambíguo da abjeção, entre afastamento e aproximação.
} 
O corpo, por muito tempo, serviu como pano de fundo para a beleza, a simetria, o desenho, as cores e os estudos realizados pelos artistas. No pós-guerra, o corpo deixa de expressar a beleza e passa a denunciála. O corpo é evidenciado naquilo que possui de mais íntimo, humano e real, entre corpos que sentem, reagem, gozam, riem, pulsam e sangram. Corpos que não observam limites ou regras, corpos tridimensionais ante aos olhos, sejam mortos, vivos ou ao vivo.

Artistas burlam as regras ao romper com os limites da higiene, da ordem, das normas e escancaram o corpo, profanando-o. A arte transita pelos caminhos abjetos, inverte os sentidos ao mostrar aquilo que não se quer ver, ao questionar aquilo que, convencionalmente, deveria estar escondido. Para isso, utiliza-se o corpo, um todo sem limites e aberto a diferentes interações e questionamentos.

A profanação está nos desenhos e gravuras de Goya, ao produzir uma infinidade de trabalhos que ressaltam a perversidade, corpos cadavéricos, corpos mutilados e expostos, corpos mortos e afetados pela guerra. A guerra deixa de ser representada como uma pintura histórica memorável, para ser apresentada em seus detalhes cruéis e chocantes.

Os excrementos, secreções e fluídos aparecem nos escritos de Marques de Sade e Georges Bataille. Na década de 1960, o excremento se torna objeto de arte ao ser comercializado a preço de ouro no trabalho Merda de Artista, de Piero
Manzoni. O corpo como questionamento e espaço de reflexão está presente no Livro de Carne, na Cancela de Carne, nas Trouxas de Sangue, entre outros trabalhos de Artur Barrio, be $\mathrm{m}$ como, nas fêmeas mutiladas das esculturas Femme Couteau, de Louise de Bourgeois. O corpo morto se apresenta plastinizado, montado, manipulado e, em alguns momentos, em movimento nas proposições de Gunther von Hagens. O corpo é levado ao limite das sensações e possibilidades através de cortes, choques e diferentes temperaturas, com o tempo e as relações existentes nas performances de Marina Abramovic. Ainda, o sangue, as vísceras e as denúncias fazem parte dos trabalhos de Karin Lambrecht e Adriana Varejão, também nas pinturas hiper-realistas de Fábio Magalhães.

A profanação do corpo e da carne também transita pelas vias da abjeção. Abjeto como aquilo que afeta a ordem simbólica, enfrenta as fragilidades do ser humano e sua fronteira com a animalidade. Liga-se ao sangue arterial e ao sangue menstrual que escorre e marca o corpo e o caminho como na escultura Tale, de Kiki Schmidt. O sangue, as fezes e o sêmen nas fotografias de Andres Serrano. Na putrefação, na lama, no cadáver, nos pedaços de animais das performances e fotografias de Rodrigo Braga. Uma série de trabalhos e artistas que problematizam, profanam os corpos e provocam diferentes reações e reflexões.

A artista francesa Gina Pane, por exemplo, utiliza o corpo como espaço para suas performances e experimentações artísticas. Não se trata de um 
corpo apenas como suporte, mas de um corpo enquanto terreno problemático de dúvidas e questões, ao mesmo tempo, terreno fértil onde aborda a mutilação, a automutilação e o sofrimento. Também, acentua o problema da violência na vida contemporânea, a vulnerabilidade e a passividade diante dela.

Na obra Action Psyché, do ano de 1974, a artista realiza cortes em seu ventre com uma lâmina. A fotografia em cores registra a performance $e$ mostra o vermelho do sangue, que escorre dos cortes longos verticais e dos cortes curtos horizontais, em contraste com a pele e a roupa branca. Em outras performances, por exemplo: Sentimental Action, 1973, a artista corta seu rosto, braços, pernas, rompe sua pele, corta sua epiderme, produz feridas em seu corpo que se torna experiência intensa e excessiva em sua vulnerabilidade.

Nos exemplos citados ao longo dos últimos cinco parágrafos, vale destacar que não se trata de realizar uma apologia à mutilação ou automutilação, acalentar as vulnerabilidades pessoais, considerar a possibilidade de insanidade por parte de quem realiza o trabalho artístico ou qualquer outra coisa do gênero. Mas sim, apontar a entrega com que muitos(as) artistas realizam seus trabalhos ao abordar as problemáticas que envolvem o conpo, inclusive na esfera da profanação.

Torna-se relevante levantar a perspectiva de Sánchez (2004), ao analisar que, quando o corpo se encontra sem mácula, com a carne e a pele fechada, íntegra, ele não instiga reflexão. Se trata de um corpo transparente, translúcido, em silêncio, sadio, o corpo da não escritura. A pele fechada é a pele calada. Já, a pele rasgada, ferida, cortada faz o corpo reclamar. O corpo ferido, que mostra a carne, que faz sair o sangue, deixa de ser um corpo comum para ser um corpo que chama atenção. Nessa condição, o corpo encontra-se opaco, ou seja, ele guarda mistérios, não se mostra totalmente, pois não se sabe o que ocorreu para que o corpo se encontrasse aberto, como um motor discursivo incessante e germinador.

Quando o artista Gina Pane traz a pele rompida, o corpo é posto em questão. Não se trata apenas de mera transgressão e agressão. A artista elege o corpo como um espaço de reflexão. A agressão causa incômodo, impacto, nojo, dúvidas, curiosidade e repulsa pelo excesso do real, por isso, muitas pessoas não possuem o desejo de interagir com a obra. Um misto de asco diante a imagem e a necessidade de continuar olhando. Não mais o deleite e a beleza da obra de arte, mas do conflito da profanação nas proposições artísticas.

O impacto de quem visualiza um trabalho, nas vias da profanação do corpo, por vezes causa dificuldade de recepção e compreensão, fato que rebate para o ensino das Artes Visuais. Ao longo da história, a arte serviu demasiadamente a beleza e ao deleite, mas há diversos trabalhos artísticos que se direcionam para outra perspectiva, onde o expectador começa a ser sacudido da sua zona de conforto. O conforto e o deleite são o contrário do que os(as) artistas citados(as) propõem, sendo que, também pode se tornar o contrário do proposto na educação e no ensino de arte na atualidade. Um objetivo premente do ensino das Artes Visuais é sacudir os estudantes da sua zona de conforto, seja por meio da história da arte e das produções de artistas, seja em propostas reflexivas que instigam a aprendizagem e permitem um posicionamento, bem como, por meio de produções dos próprios estudantes. 
Outro objetivo que pode permear constantemente o ensino das Artes Visuais está na possibilidade de ampliar e enriquecer o repertório artístico e cultural dos(as) estudantes(as). É válido partir da realidade deles, mas é fundamental ampliar seus conhecimentos sobre as artes. Nessa perspectiva, entram os questionamentos e reflexões acerca do corpo profano e profanado na "estranha fala" ${ }^{3}$ das Artes Visuais na contemporaneidade.

O corpo denuncia e questiona aquilo pelo qual todos são feitos: "(...) de carne, de bife, de sangue, de lágrimas, de suores, de merda, de inteligência, de ternura, de outras coisas ainda, ao infinito, sem que nenhuma negue as outras, ou melhor: cada uma saudando as outras" (GENET, 2002). A deflagração de Jean Genet (1910-1986), de que somos todos iguais é assustadora e certeira para elucidar o corpo, ou seja, o ser humano.

Diante das temáticas arroladas compreende-se que nada abarca a complexidade do corpo, por isso o corpo se coloca mais como problema, enigma e questão, do que como solução. Portanto, continua-se a representá-lo, a refletir sobre ele, a falar sobre o que o atinge, pois cada qual pode ter uma visão diferenciada, na perspectiva de enriquecer o ensino, o debate e a produção nas Artes Visuais.

\section{Considerações}

Ao longo da história da humanidade diferentes concepções sobre o corpo persistiram e

\footnotetext{
3 "Estranha fala", no sentido de que as Artes Visuais também falam, não uma fala falada, mas uma fala imagética, ou seja, por meio de imagens. Sendo que, as imagens podem causar estranhamentos, ainda mais na perspectiva abordada, do corpo profanado.
}

reverberaram no pensamento e nas produções artísticas. O recorte realizado para o presente artigo se deu a partir da possibilidade de se pensar o corpo como profano e profanado, por meio de concepções teóricas e dos trabalhos artísticos que reverberam tais temáticas. Então, além do recorte temático houve um recorte teórico e artístico nas obras citadas.

No decorrer do artigo abordou-se o corpo profano ligado às coisas mundanas, cotidianas, materiais e intelectuais, aos sentidos, sensações, transgressões, longe das questões consideradas sagradas e elevadas. Já, o corpo profanado, abordou-se como ligado ao corpo violado, mutilado, que reflete, enfrenta e questiona as convenções. Se o corpo profano transgride o sagrado, o corpo profanado vai além da transgressão e se apresenta como espaço violado, um corpo da escritura, marcado, rasgado, à mostra. Sendo que, ambos propõem questionamentos e reflexões, assim como, causam diferentes reações, entre elas, curiosidade, dúvida, admiração, asco e estranhamento.

Através dos exemplos levantados no texto se torna evidente que há amplos materiais nas Artes Visuais que servem de referência para debater sobre a temática do corpo. Sendo assim, o corpo profano e o corpo profanado, também podem ser abordados no contexto educativo acadêmico e escolar. A questão que persiste é: como o corpo está sendo abordado no ensino de Artes Visuais? Também há espaço para o profano e profanado, além do corpo sagrado e sublime?

O corpo, como testemunha das barbáries, não pretende explicar o que é o corpo, tão pouco 
justificar o que houve, pois traz para a arte outra proposta, onde o corpo se torna um veículo de denúncia e de múltiplos significados. A partir da barbárie, da catástrofe real, o corpo passa a denunciar a beleza, a proporção, a harmonia, o equilíbrio, passa a representar a dor, o sofrimento, as dificuldades, os ferimentos, as atrocidades onde o corpo foi e é diretamente atingido e afetado. Os corpos foram atravessados pela guerra, pelo horror do genocídio, pelas agressões sofridas que denunciam o ser humano enquanto carne, pele e corpos que sentem, sofrem, possuem necessidades, vivem situações extremas, se entregam, resistem, transitam, se relacionam com os outros e com o mundo. Uma das maneiras de se discorrer acerca do corpo, principalmente no pós-guerra, é por meio da profanação.

Principalmente no pós-guerra, o próprio corpo é colocado em questão, em xeque, o próprio corpo se impõe enquanto problema, como enigma, como problemática de análise. A dificuldade está no fato do corpo se oferecer mais como um problema do que solução, mais como enigma, do que saída. Aqui reside a necessidade de continuar a representar, pesquisar, produzir, perguntar, ensinar, debater e ampliar o repertório sobre o corpo, esse espaço fértil de inesgotáveis reflexões e representações.

Recebido em: 28/04/2018

Aceito em: 06/08/2018

\section{Referências Bibliográficas}

ADORNO, Theodor W. Dialética Negativa. Rio de Janeiro: Jorge Zahar Ed., 2009.

GENET, Jean. Rembrandt. Rio de Janeiro: José Olympio, 2002.
KRISTEVA, Julia. Poderes de la Perversion. Buenos Aires: Catálogos, 1988.

LEVINAS, Emanuel. Algunas reflexiones sobre la filosofia del hitlerismo. Buenos Aires: Fundo de Cultura Econômica de Argentina, 2001.

MANGUEL, Alberto. Lendo Imagens - Uma Historia de Amor e Ódio. São Paulo: Companhia das Letras, 2009.

MARCUSE, Herbert. Poesia lírica após Auschwitz. Traduzido por Luís Gustavo Guadalupe Silveira. Revista.doc., $\quad$ ก. 07 janeiro/junho de 2009.

MERLEAU-PONTY, Maurice. O Olho e o Espírito. São Paulo: Cosac \& Naif, 2004.

MERLEAU-PONTY, Maurice. A Dúvida de Cézanne. In: Textos Selecionados. São Paulo: Nova Cultura, 1989. (Os Pensadores).

MERLEAU-PONTY, Maurice. Fenomenologia da Percepção. São Paulo: Martins Fontes, 1994.

MERLEAU-PONTY, Maurice. O Visível e o Invisível. São Paulo: Editora Perspectiva, 2000.

SÁNCHEZ, Pedro A. Cruz. La vigília del cuerpo: arte y experiência corporal em La contemporaneidad. Murcia, Espanha: Tabvlarivm, 2004.

SELIGMANN-SILVA, Márcio; NESTROVSKI, Arthur (orgs). Catástrofe e representação: Ensaios. São Paulo: Escuta, 2000. 